\title{
Highlights
}

- Significant effects of grape maturity on astringency, fruity and oxidation wine aromas

- Oxidation aromas appeared in wines elaborated with grapes prematurely harvested

- Oxidation aroma is positively correlated to the concentration of Strecker aldehydes

- Lower levels of aldehyde-reactive polyphenols are related to higher oxidation nuances

- Astringency is positively correlated to ethanol, tannin and anthocyanin-derivatives 


\section{Effect of grape maturity on the sensory and chemical features: The case - of \\ 2 Moristel wines}

3 Sara Ferrero-del-Teso ${ }^{\mathrm{a}}$, Ignacio Arias $^{\mathrm{b}}$, Ana Escudero ${ }^{\mathrm{b}}$, Vicente Ferreira ${ }^{\mathrm{b}}$, Purificación

4 Fernández-Zurbano ${ }^{\mathrm{a}}$, María-Pilar Sáenz-Navajas ${ }^{\mathrm{b} *}$

5 anstituto de Ciencias de la Vid y del Vino (ICVV) (Universidad de La Rioja-CSIC-

6 Gobierno de La Rioja), Carretera de Burgos Km. 6, Finca La Grajera, 26007 Logroño,

7 La Rioja, Spain.

8 baboratorio de Análisis del Aroma y Enología (LAAE), Department of Analytical

9 Chemistry, Universidad de Zaragoza, Instituto Agroalimentario de Aragón (IA2)

10 (UNIZAR-CITA), Associate unit to Instituto de las Ciencias de la Vid y del Vino

11 (ICVV) (UR-CSIC-GR), c/ Pedro Cerbuna 12, 50009 Zaragoza, Spain

12

13 *Corresponding author: maria@saenz.info; masaenn@unizar.es

14 


\section{Abstract}

16 Among the different grape factors involved in wine quality, the present work is focused

17 on evaluating the effect of grape maturity on wine flavour and how these sensory effects

18 are related to wine chemical composition.

19 Moristel grapes were collected from two vine blocks, with a priori maximal variability

20 in terms of grape quality, at 4 and 3 points of maturation, respectively. Wines were

21 elaborated in triplicate yielding 21 wine samples. Sensory characterisation of samples was carried out by a panel of trained panellists following the rate-all-that-apply method.

23 Volatiles and non-volatiles with known sensory impact on wines were quantified.

24 Grape maturity generated significant sensory effects on wine astringency and fruity 25 aroma including raisin, black and red fruit. Interestingly, a significant effect on 26 oxidation nuances revealed a general pattern in the appearance of higher oxidation 27 aromas in wines elaborated with grapes prematurely harvested. This attribute is related 28 to free acetaldehyde, methional, phenylacetaldehyde and isoaldehydes and aldehydereactive polyphenols content. The presence of raisin aroma is linked to $\beta$-damascenone,

30 which is suggested to be formed during the on-vine dehydration process. Astringency is

31 related to ethanol content, tannin activity (measured as the interaction of tannins with a 32 hydrophobic surface) and the content in anthocyanin-derivative compounds.

35 Keyword: wine; aroma; oxidation; astringency; tannin activity 


\section{Introduction}

37 Grape composition is an important factor influencing sensory characteristics of wines 38 (Niimi, Boss, Jeffery, \& Bastian, 2017). Thus, selecting the optimal point to harvest berries with the greatest potential to yield wines with desired sensory properties is a major issue for winemakers. The measurement of the basic chemical parameters of grapes (such as $\mathrm{pH}$, total acidity, colour intensity, phenolic content) to determine ripeness prior to harvest is a standard industry practice. However, these conventional measurements are not enough to predict wine features (Pérez-Magariño \& GonzálezSan José, 2006). Phenolic compounds together with sensory-active volatile compounds are generally considered to be major determinants of the quality of red wines (SáenzNavajas et al., 2015). However, a clear relationship between aroma precursors and the phenolic composition present in grapes, and wine sensory characteristics including aroma, taste or chemesthesic sensory properties (including thermal, pain-related or astringency-related sensations) has not been yet established. Concerning the potential aromatic quality of grapes, it is a factor poorly understood. Winemaking grapes present mostly neutral aroma, which is the result of the presence of very low quantities of a long list of aromatic compounds such as furaneol, $\beta$-damascenone, terpenols, benzenoids or phenols among others. Besides these molecules, grapes contain a complex series of specific aroma precursors. These nonvolatile molecules, known as precursors, can generate an aromatic molecule by 1 ) the break of chemical bonds (including glycoside, S-derivatives of cysteine or glutathione or S-methionine and other precursors of dimethyl sulphur) and/or 2) spontaneous molecular reassemble (by $\mathrm{pH}$ effect or esterification) (Parker, Capone, Francis, \& Herderich, 2018). These precursors play an essential role in wine aroma, but the effect of grape maturity on aroma grape potential is

60 far from being clear. Firstly, because the analytical tools to quantify these precursors are 
61 still being developed and secondly because precursor concentration in juices is not 62 directly correlated to the aroma compounds found in wines (Alegre, Ferreira, \& 63 Hernández-Orte, 2019).

64 Regarding phenolic compounds, tannins (proanthocyanidins) and anthocyanins 65 constitute the most abundant classes in grapes. Anthocyanins are released from grape 66 skins, whereas proanthocyanidins are released from both skins and seeds. Accumulation 67 of anthocyanins set in at véraison and decline during overripening. Proanthocyanidins 68 mainly accumulate before véraison (Fournand et al. 2006). The ripeness of the grapes 69 has an important effect on the kind and extractability of phenolic compounds into the 70 wine. The extractability of proanthocyanidins from seeds decreases with ripeness, 71 probably due to oxidation phenomena and gradual seed lignification that hinder their 72 extraction. Differently, the extractability of skin phenolics increases with ripening, 73 which is attributed to the action of enzymes by degrading the wall of skin cells (Gil et 74 al., 2012).

75 Hence, grape maturity represents an important factor determining grape composition 76 and consequently composition and sensory properties of wines and hence wine quality.

77 In terms of grape cultivars, Moristel is a minor variety suggested to originate from 78 Aragon (north-east Spain), where it is basically found in the Somontano region 79 (Robinson, Harding, \& Vouillamoz, 2012). This is a cultivar with reasonably good 80 resistance to drought, pests and diseases, presenting a late ripening with the onset of 81 anthocyanins taking place at low sugar levels (García, Zheng, Balda, \& Martinez De 82 Toda, 2017). These make Moristel an interesting alternative cultivar to be grown in 83 warm climates, however scarce scientific literature can be found about its potentiality. 84 In this context, the aim of the current study was to determine the effect of Moristel 
grape maturity on the sensory attributes of final wines and to relate these sensory

86

87

88

89

90

91

92

93 changes with chemical composition considering Moristel variety as case study.

\section{Material and Methods}

2.1. Site location and winemaking

The experiment took place in Barbastro situated in Somontano region (Huesca, Spain) during 2017 harvest. Two vineyard blocks (BLA and BLB) with a priori maximal diversity in quality were selected based on historical data and criteria derived from the commercial system Dyostem ${ }^{\circledR}$ (Vivelys, France). According to commercial information, this tool monitors sugar loading and changes in the colour of the fruit to classify grape quality and determines the optimal harvest date. Moristel grapes were handpicked at four points for BLA (BLA_1; BLA_2; BLA_3 and BLA_4) and at three points for BLB (BLB_1; BLB_2; BLB_4), each point separated by one or two weeks. According to the commercial system, the second point of maturity (BLA_2, BLB_2) was the optimal point to harvest, thus it was decided to harvest one week before (BLA_1, BLB_1) and one (BLA_3) and/or two (BLA_4, BLB_4) weeks after to have grapes with different maturity levels and thus with a priori maximal variability in chemical composition. One hundred and fifty kilograms of fruit were collected at each harvest date. Grapes were processed (destemmed/crushed) the same day, and the fruit was divided into three separate lots. Wines were elaborated in 75-litre stain-less steel tanks, in triplicate. To each tank (total of 21), sulphur dioxide was added to get a total concentration of $50 \mathrm{mg} \mathrm{L}^{-1}$. The following day of harvest all tanks were inoculated with Lalvin ICVD 254 (Lallemand) at $10^{6}$ cells $\mathrm{ml}^{-1}$ and pectolytic enzyme at $0.8 \mathrm{~mL} \mathrm{Hl}^{-1}$. Alcoholic fermentations $(\mathrm{FOH})$ took place on skins for 10 days, in average. Once alcoholic fermentation was finished wines were inoculated with malolactic bacteria (Oenococcus oeni) strain Lalvin VP41 (Lallemand). Wines were bottled ca. 3 months 
110 after $\mathrm{FOH}$ (free $\mathrm{SO}_{2}$ adjusted to $30 \mathrm{mg} \mathrm{L}^{-1}$ ). Wines were bottled and closed with natural

111 cork closures.

112 2.2. Sensory analysis

113 2.2.1. Participants

114 Seventeen panelists from Instituto de Ciencias de la Vid y del Vino (ICVV) and

115 Universidad de La Rioja (Spain)_participated in sensory description. They were mainly

116 last-year oenology students and oenologists (60\% women, ranging from 22 to 34 years

117 of age, average $=28$ ).

$118 \quad$ 2.2.2. Panel training and generation of sensory attributes

119 Participants attended a total of 6 training sessions (1h30 each session) over three weeks.

120 During this period, panellists worked in two subgroups following the same guidelines.

121 The first session was devoted to generate aroma terms differing among samples.

122 Therefore, participants were presented simultaneously with the 21 wines of the study

123 and were asked to sort them based on their aroma similarity according to a sorting task.

124 Once groups were built, they described them with two or three descriptive aroma terms

125 (avoiding hedonic terms). Terms generated were gathered and grouped in categories

126 according to semantic similarities. This process was performed individually by three

127 experienced researchers, who through a triangulation task (Abric, 2003) achieved a final

128 consensual list of 12 terms that included: fresh vegetables (green pepper), red fruit

129 (strawberry, cherry, raspberry), white fruit (apple, pear), black fruit (blackberry,

130 blackcurrant), dried fruit (raisin, prune), fresh grass, oxidation (acetaldehyde, boiled

131 potato, honey, overripe apple), roasted/smoky, reduction (cauliflower, rotten eggs),

132 spicy (black pepper, nutmeg, clove), undergrowth (mouldy, mushroom) and alcohol

133 (ethanol, spirit-like). During the following training sessions, reference standards

134 (prepared at Laboratorio de Análisis del Aroma y Enología of Universidad de Zaragoza) 
135 representative of the 12 selected aroma terms as well as of $\underline{3}$ taste (sweet, sour, bitter)

136 and 4 chemesthesic (astringency, alcoholic feeling, viscosity/body) terms were

137 presented. For in-mouth terms, solutions containing different concentrations of table

138 sugar $\left(0-7 \mathrm{~g} \mathrm{~L}^{-1}\right)$ for sweetness, tartaric acid $\left(0_{-}-3 \mathrm{~g} \mathrm{~L}^{-1}\right)$ for acidity, quinine sulphate $\left(0_{-}\right.$

$\left.139-40 \mathrm{mg} \mathrm{L}^{-1}\right)$ for bitterness and potassium, aluminium sulphate $\left(0_{-}-5 \mathrm{~g} \mathrm{~L}^{-1}\right)$ for

140 astringency, absolute alcohol $(0-15 \% \quad \mathrm{v} / \mathrm{v})$ for alcoholic feeling and

141 carboxymethylcellulose (0-1.5 $\left.\mathrm{g} \mathrm{L}^{-1}\right)$ for viscosity/body stimuli, were prepared. During

142 a typical training session, panellists were presented with references illustrating the

143 different aroma, taste and chemesthestic terms and 2-4 wines were firstly individually

144 described and then ratings were discussed until achieving consensus.

$145 \quad$ 2.2.3. Wine description

146 The 21 wines (7 different wines elaborated in triplicate) were described in duplicate

147 during four sessions (replicated samples were presented in different sessions). Each

148 session was split into two parts (45 min each) (5-6 samples per part), which were

149 separated by an imposed pause of $10 \mathrm{~min}$. Participants were asked to taste and rate the

150 intensity of exclusively those terms (out of 18) that applied to the sample on a seven-

151 point scale according to Rate-all-that-apply (RATA) methodology (Ares et al. 2014).

152 Terms that did not apply to the sample were allocated a value of zero when collecting

153 data. To avoid bias due to order of presentation, terms in the list appeared in different

154 and randomised order for each assessor. The use of a sip (rinsing solutions: water and 1

$155 \mathrm{~g} \mathrm{~L}^{-1}$ pectin solution) and spit protocol between each sample was imposed as described

156 elsewhere (Colonna, Adams, \& Noble, 2004). All participants evaluated the 21 in

157 duplicate samples in a sequential monadic manner. Twenty-mL samples were served in

158 dark wine glasses labelled with 3-digit random codes and covered with plastic Petri

159 dishes according to a random arrangement, different for each participant. Samples were 
160 served at room temperature and evaluated in a ventilated and air-conditioned tasting

161 room (at around $20^{\circ} \mathrm{C}$ ).

162 2.2. 1 . Sensory data analysis

163 A three-way ANOVA for each of the sensory attributes evaluated involving wines (W),

164 judge $(\mathrm{J})$ and replicate $(\mathrm{R})$ as fixed factors and all first order interactions was calculated

165 to confirm panel performance with the 21 wines (in duplicate) of the study. The

166 replicate effect was only significant $(\mathrm{P}=0.033)$ for the term roasted/smoky, indicating a

167 global consistent assessment of attributes and reflecting the reproducibility of the panel.

168 Thus, the average data between replicated samples was calculated and considered in

169 further analyses. The wine-by-judge interaction (WxJ) was significant for white fruit,

170 roasted/smoky, undergrowth, reduction, oxidation and body/viscosity. A PCA run on

171 these attributes (judges in columns and wines in rows) revealed that judges' projections

172 were spread over the loading plot for white fruit, undergrowth, reduction and

173 body/viscosity, while they were grouped together for the other two attributes. This

174 indicates that there are differences in the use of the scale for roasted/smoky and

175 oxidation. Differently, for white fruit, undergrowth, reduction and body/viscosity there

176 are differences in their interpretation, which suggests that assessors may need more

177 training with respect to these four attributes. These terms were not considered in

178 subsequent analysis.

179 Then, to find discriminant sensory attributes for the wines a two-way ANOVA

180 (panellists as random and wines as fixed factors) was calculated for each of the

181 remaining 14 terms of the list. Then, for discriminant terms, pair-wise comparison test

182 (Fischer test) was applied (5\% risk) for significant effects. All statistical analyses were

183 performed using XLSTAT (2018).

$184 \quad 2.3$ Chemical analysis 
186 Grapes: Sugar content in grapes was analysed by Infrared Spectrometry with Fourier

187 Transformation with a WineScanTM FT 120 (FOSS®, Barcelona, Spain), which was

188 previously calibrated with the official OIV methods.

189 Wines: Total polyphenol index (TPI) was estimated as absorbance at $280 \mathrm{~nm}$ (Ribéreau-

190 Gayon, 1970) and colour intensity (CI) as the sum of absorbance at 420, 520 and 620

$191 \mathrm{~nm}$ (Glories, 1984). For TPI determination, the abs at $280 \mathrm{~nm}$ of samples diluted 1:100

192 in deionised water was measured in 1-cm-quartz cuvettes. Reducing sugars, ethanol

193 content, $\mathrm{pH}$, malic and lactic acid as well as titratable and volatile acidities were

194 analysed by Infrared Spectrometry with Fourier Transformation with a WineScanTM

195 FT 120 (FOSS ${ }^{\circ}$, Barcelona, Spain), which was previously calibrated with the official

196 OIV methods.

197 2.3.2. Chemical characterisation of non-volatile compounds

198 2.3.2.1. Determination of anthocyanin-derived pigments

199 Determination of monomeric (MP), small polymeric pigments (SPP) and large 200 polymeric pigments (LPP) in wines and fractions was carried out as described 201 elsewhere (Harbertson, Picciotto, \& Adams, 2003). MPs were the group of compounds 202 bleachable with bisulphite, while SPP and LPP were resistant to bisulphite bleaching.

203 SPP did not precipitate with ovoalbumin, different to LPP. Levels of MP, SPP, and LPP 204 were expressed as absorbance at $520 \mathrm{~nm}$.

205 2.3.2.2. Mean degree of polymerisation (mDP) of tannins

206 Acid-catalysed degradation in the presence of toluene- $\alpha$-thiol was performed according 207 to the method described by Labarbe et al. (1999) but with some modifications as 208 described by Gonzalo-Diago, Dizy, \& Fernandez-Zurbano (2013). Quantification was 209 done in the negative mode from the extracted ion chromatogram (EIC) for flavan-3-ols 
210 and in the positive mode for malvidin-3-O-glucosiyde. The area under the peaks of 211 malvidin-3-O-glucosiyde and flavan-3-ol monomers (terminal units) before and after 212 thiolysis as well as toluene- $\alpha$-thiol adducts (extension units) released from the

213 depolymerisation reaction were integrated. Calibration curves were established with 214 malvidin-3-O-glucosiyde, (+)-catechin, (-)-epicatechin, (-)-epicatechin-3-O-gallate,

215 and (-)-epigallocatechin. In the absence of the standards of the thiol derivatives and

216 considering the fact that the thiolytic derivatives were shown to have similar response

217 factors as the correspondent monomeric units, their concentrations were calculated from

218 the respective monomer calibration curves. The mean degree of polymerisation $(\mathrm{mDP})$

219 was calculated as the ratio of total units (extension + terminal) to terminal units

220 (calculated as the difference between before and after thiolysis). The percentage of

221 tannins linked to malvidin-3-O-glucosiyde (\%T-M) was calculated as the molar ratio of 222 malvidin-3-O-glucosiyde linked to tannins (calculated as the difference before and after thiolysis) to the sum of total units of terminal malvidin-3-O-glucosiyde and extension +

224 terminal units of (+)-catechin, (-)-epicatechin, (-)-epicatechin-3-O-gallate, and (-)225 epigallocatechin (i.e. total units of tannins). The percentage of procyanidins (\%PC) was 226 calculated as the ratio of total units (extension and terminal) of catechin and epicatechin 227 to total units of tannins. The percentage of prodelphinidins (\%PD) and galloylated (\%G)

228 units as the ratio of total units of PD and G to the total units of tannins, respectively.

$229 \quad 2.3 .2 .3$. Tannin concentration and activity

230 Concentration and activity of tannins were estimated by a UHPLC-UV-Vis method 231 following the method proposed by Revelette, Barak, and Kennedy (2014). Tannin 232 activity is related to the thermodynamics of interaction between tannins and a 233 hydrophobic surface (polystyrene divinylbenzene HPLC column).

234 2.3.3. Chemical characterisation of volatile compounds 
236 The determination by headspace-SPME-GC-MS of total (free plus bound) forms of

237 different odour-active carbonyls such as isobutyraldehyde, 2-methylbutanal, 238 isovaleraldehyde, methional, phenylacetaldehyde, and diacetyl in wine was carried out 239 as is described in the method proposed by Bueno, Zapata, and Ferreira (2014).

$240 \quad$ 2.3.3.2. Determination of major volatile compounds

241 Major volatile compounds were isolated by liquid-liquid extraction and analysed in a 242 gas chromatograph with flame ionization detector (GC-FID) following the method 243 described by Ortega, López, Cacho, and Ferreira (2001) but with some modifications.

244 2.3.3.3. Determination of trace aroma compounds

245 Trace aroma compounds were isolated through solid-phase extraction (SPE) and 246 analysed by gas chromatography coupled to a mass spectrometry detection system (GC-

247 MS) as explained by López et al. (2002).

$248 \quad$ 2.3.3.4. Determination of alkylmethoxypyrazines

249 Alkylmethoxypyrazines were quantified using stir bar sorptive extraction (SBSE), 250 followed by thermal desorption gas chromatography coupled with mass spectrometry 251 (TD-GCxGC-MS) (Wen, Ontañon, Ferreira, \& Lopez, 2018). Stable isotope dilution 252 analysis was used for quantification (with selective mass fragments). The compounds analysed were 2-isobutyl-3-methoxypyrazine (IBMP), 2-isopropyl-3-methoxypyrazine

254 (IPMP) and rotundone.

\subsubsection{Data analysis of chemical data}

256 Quantitative data of the 72 volatile compounds were transformed into Odour Activity

257 Values (OAV), by dividing by their corresponding sensory thresholds (ST) (tabulated in

258 Table 1). In the case of concentrations below detection (DL) or quantification (QL)

259 limits, OAV was calculated as DL/ST or QL/ST, respectively. In order to rank 
260 compounds in accordance to their discriminatory ability, the quotients between the 261 maximum and minimum OAV were worked out for each compound (OAV minimum <

2620.2 , this value was arbitrary used for avoiding quotients with no sense from a sensory 263 point of view, especially when OAVmin are zero).

264 In order to facilitate the correlation of chemical and sensory spaces, the chemical space 265 of volatile molecules was simplified by creating aroma vectors. Aroma vector is defined as "a perceptual unit constituted by one or several molecules with similar aroma descriptors, which altogether and in an integrated form, are responsible for a specific set of sensory features of a type of products; wine in our case" (Ferreira, SáenzNavajas, \& de La Fuente, 2019). Aroma vectors are built by grouping aroma compounds with similar chemical structure and odour properties based on Ferreira, Sáenz-Navajas, and de La Fuente (2019). Therefore, the individual OAV for each compound belonging to each vector is firstly calculated and aroma vectors are the sum of OAVs of compounds within each vector. Table 1 shows the 13 aroma vectors built. Another 11 compounds with known sensory impact were studied individually: $\beta$ 275 damascenone (baked apple, dry plum), $\beta$-ionone (violets, berry), ethyl 276 dihydrocinnamate (sweet, balsamic), Z-3-hexenal (leaf, grassy), diacetyl (buttery, milky, 277 yogurt), methional (potato, oxidised, overripe), phenylacetaldehyde (honey, oxidized), 278 acetaldehyde (green apple, oxidized), isoamyl acetate (fruit, banana), phenylethyl 279 acetate (floral, rose, sweet) and $t$-whiskylactone (oaky, coconut).

280 Discrimination ability of individual compounds and vectors among wines was evaluated 281 by calculating the ratio OAVmax/OAVmin. Only values $>2$ were considered to have the 282 ability to discriminate among wines. Besides, only compounds or vectors with OAV> 1 283 in at least one wine were considered to have a potential sensory impact. 
284 For compounds with OAVmax/OAVmin $>2$ and $\mathrm{OAV}>1$ in at least one wine, one-way

285 ANOVA (wines as fixed factors) was calculated to find compounds and vectors able to 286 explain the aroma properties of the wines. Pair-wise comparison test (Fischer test) was 287 applied (5\% risk) for significant effects. All statistical analyses were performed using 288 XLSTAT (2018).

289 Finally, a principal component analysis (PCA) was calculated with the mean sensory 290 scores (of the 17 panellist) of the significant sensory aroma terms as active variables and with significant volatile compounds or vectors as supplementary variables. All analyses were carried out with XLSTAT (2018 version).

\subsection{Colour measurement}

294 The absorbance spectra of this set of wines were measured. Measurements were carried 295 out in a Shimazdu UV-1800 (Shimadzu Corporation, Tokyo, Japan), using 0.2-cm pathlength crystal cuvettes. Measurements were taken every $1 \mathrm{~nm}$ between 380 and $780 \mathrm{~nm}$.

297 Wine samples had been previously clarified by passing wine through $0.45 \mu \mathrm{m}$ filters. 298 From the spectra, the colour coordinates were calculated using the CIE method, with the 299 CIE $196410^{\circ}$ standard observer and the illuminant D65, according to the OIV. The

300 values correspond to the degree of wine lightness $\left(\mathrm{L}_{10} *\right)$ and the degree of red (when $\mathrm{a}_{10} *>0$ ), green (when $\mathrm{a}_{10} *<0$ ), yellow (when $\mathrm{b}_{10} *>0$ ), and blue (when $\mathrm{b}_{10} *<0$ ) colour.

\section{Results and discussion}

303 3.1. Effect of grape maturity on conventional parameters of grapes and wines

304 Grapes from block A, BLA, reached higher levels of sugars $\left(267 \pm 3 \mathrm{~g} \mathrm{~L}^{-1}\right)$ than block B $305\left(250 \pm 6 \mathrm{~g} \mathrm{~L}^{-1}\right)$. Significant effects $(\mathrm{P}<0.05)$ of the maturity point (i.e. harvest point) on 306 sugar content were observed on both blocks, presenting later points of harvest (BLA_4 and BLB_4) the highest levels in both cases (Table 2). These data are well correlated

308 with the ethanol content present in the final wines (Table 2), which reached maximal 
309 values (15.8 and $13.7 \%$, v/v, in BLA_4 and BLB_4, respectively) at these points.

310 Interestingly, there is a relatively ample variation $(3.4 \%, \mathrm{v} / \mathrm{v})$ of ethanol content among

311 the studied wines, which is significantly correlated with total polyphenol index (TPI)

$312(\mathrm{r}=0.97 ; \mathrm{P}<0.001)$. This fact can be related to the higher capacity of ethanol to extract

313 polyphenolic compounds.

314 A significant effect of titratable acidity on maturity point was observed in both blocks,

315 presenting the initial harvest points (BLA_1, BLB_1) the highest levels (Table 2). This

316 parameter ranges from 5.8 to $6.7 \mathrm{~g} \mathrm{~L}^{-1}$ (expressed as tartaric acid) in the studied wines,

317 which is within the normal values found in Spanish wines (Sáenz-Navajas, Avizcuri,

318 Ferreira, \& Fernández-Zurbano, 2012; Sáenz-Navajas, Fernandez-Zurbano, Tao, Dizy,

$319 \&$ Ferreira, 2010). Differently, no significant effect of grape maturity on $\mathrm{pH}$ nor volatile

320 acidity of wines was observed for neither of the two blocks studied. Interestingly, the

321 variety object of study shows low pH values (range: 3.2-3.3) in comparison with other

322 Spanish wines elaborated with more common varieties such as Tempranillo, Grenache,

323 Cabernet Sauvignon or Syrah among others, which are reported to range between 3.3

324 and 4.0, while acetic acid, that ranges from 0.3 to $0.5 \mathrm{~g} \mathrm{~L}^{-1}$ (expressed as acetic acid), is

325 within values reported in literature for Spanish wines (Sáenz-Navajas et al., 2010, 326 2012).

327 Based on the content in reducing sugars, which ranged from 1.6 to $2.6 \mathrm{~g} \mathrm{~L}^{-1}$, it can be 328 confirmed that alcoholic fermentation was properly carried out yielding dry wines in all 329 cases $\left(<5 \mathrm{~g} \mathrm{~L}^{-1}\right)$. Noteworthy is that wines elaborated with grapes from block B, BLB, 330 underwent malolactic fermentation, providing wines with an average of $0.5 \mathrm{~g} \mathrm{~L}^{-1}$ of 331 lactic acid. Differently, wines from block A had difficulty to finish malolactic 332 fermentation, showing low levels of lactic acid $\left(<0.3 \mathrm{~g} \mathrm{~L}^{-1}\right.$ in all cases). 
334 3.2. Effect of grape maturity on polyphenolic composition and colour coordinates of 335 wines

336 Table 3 shows variables related to the characterisation of wine polyphenolic compounds

337 and colour coordinates. The values of tannin activity, which is measured as the enthalpy 338 of interaction between polyphenols and a hydrophobic surface (Revelette et al., 2014), 339 range between 854 and $2751-\mathrm{J} \mathrm{mol}^{-1}$, which are relatively low in comparison with 340 other studies with Cabernet Sauvignon (1430-4820 $-\mathrm{J} \mathrm{mol}^{-1}$ ) (Watrelot, Byrnes, 341 Heymann, \& Kennedy, 2016) or Merlot wines (3170-4060 - J mol ${ }^{-1}$ ) (Sáenz-Navajas et 342 al., 2018). This property has shown to decrease with both barrel ageing and 343 microoxygenation (Watrelot et al., 2016; Sáenz-Navajas et al., 2018) attributed to tannin 344 oxidation (Yacco, Watrelot, \& Kennedy, 2016). Concerning tannin concentration and 345 pigmented tannins, which range from 1993 to $4188 \mathrm{mg} \mathrm{L}^{-1}$ and $618-1138 \mathrm{mg} \mathrm{L}^{-1}$, 346 respectively in the studied wines, are significantly lower $(\mathrm{P}<0.01)$ than values found in 347 Cabernet Sauvignon (2750-6160 mg L ${ }^{-1}$ ) and Merlot wines (4390-4940 mg L ${ }^{-1}$ ) 348 (Watrelot et al., 2016; Sáenz-Navajas et al., 2018) for tannins and in oaked aged 349 Cabernet Sauvignon for pigments $\left(8300-12700 \mathrm{mg} \mathrm{L}^{-1}\right)$. These data show that the 350 Moristel wines studied present relatively low levels of polyphenols in comparison with 351 other common varieties such as Cabernet Sauvignon or Merlot. The relatively low concentration of tannins seem to be the responsible for the low $b_{10} *$ values (which measures yellow colour) and high values of the $\mathrm{L}^{*}$ coordinate (measures wine

354 luminosity, being higher in clearer wines) in comparison with other young Spanish red 355 wines (Soto Vázquez, Río Segade, \& Orriols Fernández, 2010). Differently, the red 356 colour of these wines, measured by the $a_{10} *$ coordinate is relatively high $\left(a_{10} *=37-59\right)$ in 357 comparison with reported young Mencía wines $\left(a_{10} * 39-46\right)$, which could be in part 358 related to the lower $\mathrm{pH}$ (average $\mathrm{pH}=3.3$ vs 3.8 ) of Moristel wines. To this concern, 
359 lower $\mathrm{pH}$ values favours the presence of flavylium cation species, which contributes to

360 red colour.

361 Significant effects of maturity level on all the variables studied are observed for block

362 A, while - Differently, for block B, only tannin activity, and coordinate L*, changed 363 significantly. Interestingly, tannin activity is inversely correlated with tannin

364 concentration, pigmented tannins and mean degree of polymerisation $(\mathrm{mDP})$ in block $\mathrm{A}$,

365 while in block $\mathrm{B}$, it decreases with maturity point, when the rest of polyphenolic 366 measurements do not experiment any significant change. These results suggest that

367 tannin activity is a very interesting parameter that can help controlling grape maturity, 368 especially because it is independent from other polyphenolic chemical variables

369 including concentration of tannins or pigments and mean degree of polymerisation.

370 In general, it is observed that the evolution of the parameters measured are block 371 dependent and no generalisation concerning the effect of grape maturity can be drawn.

373 3.3. Effect of grape maturity on wine sensory properties

374 Figures 1a and $\underline{1 \mathrm{~b}}$ show the flavour (aroma, taste or mouthfeel) descriptors that present 375 significant differences among wines elaborated with grapes harvested at different points 376 of maturation for the two blocks studied: BLA and BLB, respectively. Significant 377 effects of grape maturity are observed on raisin $(\mathrm{F}=3.41 ; \mathrm{P}<0.05)$ and oxidation $378(\mathrm{~F}=2.93 ; \mathrm{P}<0.05)$ aromas as well as on astringency $(\mathrm{F}=6.90 ; \mathrm{P}<0.01)$ for block $\mathrm{A}$. For 379 block $\mathrm{B}$ significant effects on oxidation aromas $(\mathrm{F}=12.5 ; \mathrm{P}<0.001)$ and fruity nuances 380 including raisin $(\mathrm{F}=3.39 ; \mathrm{P}<0.05)$, red fruit $(\mathrm{F}=4.32 ; \mathrm{P}<0.05)$ and black fruit $(\mathrm{F}=4.82$;

$381 \mathrm{P}<0.05)$ as well as on astringency $(\mathrm{F}=4.05 ; \mathrm{P}<0.05)$ are observed. It is interesting 382 important to note that the sensory effects of grape maturity on most flavour attributes,

383 including fruity aromas as well as astringency, are block dependent. Interestingly, in 
384 Figure 2, a general pattern of appearance of oxidation nuances in wines elaborated with 385 grapes harvested at earlier points, such as BLA_1, BLB_1 and BLB_2, is observed.

386 These oxidation nuances, changemove-_to fresh fruits (black or red fruit) in wines

387 elaborated with grapes harvested latter in both blocks (BLA_3 and BLB_4), and finally,

388 overripe grapes obtained in BLA generated raisin-like aromas.

389 Considering that young red quality is positively linked to fruity aromas and negatively

390 to oxidation and dried fruit nuances (Sáenz-Navajas, Gonzalez-Hernandez, Campo,

391 Fernández-Zurbano, \& Ferreira, 2012), results suggest that the optimal point of harvest

392 would be BLA_3 for Block A and BLB_4 for Block B. This result differs from the

393 commercial system employed as it suggested earlier points of maturity: BLA_2 and

394 BLB_2 as optimal points.

395 To gain insights into the sensory-active compounds driving such sensory differences,

396 further relationships between sensory and chemical variables were explored.

397 3.3. Relationship between sensory and chemical variables

$398 \quad 3.3 .1$. Aroma properties

399 The study of the volatile composition of the twenty-one wines has provided quantitative

400 data for 72 compounds (Table 4). Part of these compounds were grouped into 13 aroma

401 vectors as detailed in Table 1, while other eleven compounds with known sensory

402 impact by themselves were individually considered. Among these 24 variables, only 13

403 of them were expected to explain the aroma differences perceived among the 21 wines

404 studied (Table 5). Firstly, because they were above their sensory threshold (OAV >1)

405 and secondarity because the difference in odour activity among wines was important 406 enough to induce sensory differences (measured as the ratio of OAVmax/OAVmin).

407 Figure 2 shows the PCA with these 13 volatile-related parameters projected as active 408 variables and four aroma-related variables (raisin, red and black fruit and oxidation) 
409 projected as illustrative variables. As can be seen in the plot, the first principal 410 component (PC1), explaining $75 \%$ of the total variance, confronts samples with black 411 and red fruity aromas (projected on the right side of the plot) to wines projected on the 412 left part of the plot with dried fruit (BLA_4) notes and oxidised nuances (BLA_1 and 413 BLA_2; BLB_1 and BLB_2). These fresh fruity aromas are positively correlated to the 414 isoamyl acetate compound (with banana-like aroma), which has been described to be an 415 undeniable contributor to fruity nuances in young red wines (Ferreira et al., 2002). 416 Different ethyl ester profiles are suggested to be the responsible for the appearance of 417 specific red (higher levels of linear ethyl esters) or black (higher levels of branched 418 ethyl esters) fruit aromas (Pineau, Barbe, Van Leeuwen, and Dubourdieu, 2009). 419 However, such differences are not observed in the studied wines. Differently, sample 420 BLA_1, with the highest level of ethyl esters, present outstanding oxidation nuances 421 that are also present in samples BLB_1, BLB_2 and BLA_2. These oxidation notes can 422 be easily explained in terms of aldehydes including phenylacetaldehyde, and 423 isoaldehydes, free acetaldehyde and methional. This suggests a possible 424 masking/suppressor effect generated by the aldehydes (Culleré, Cacho, \& Ferreira, 425 2007) as well as the acetic acid vector (San Juan, Ferreira, Cacho, \& Escudero, 2011) on 426 the fruity character of ethyl esters, specially of BLA_1.

427 The appearance of oxidation nuances in wines elaborated with grapes harvested at 428 earlier points can be explained in terms of higher levels of oxidation-related aldehydes. 429 Interestingly, this observed wine oxidation seems to be related to the presence of lower 430 polyphenolic contents. More specifically, the levels of both the isoaldehyde vector and 431 phenylacetaldehyde present significant $(\mathrm{p}<0.05)$ negative linear correlations with total 432 polyphenol content (TPI) ( $\mathrm{r}=-0.886, \mathrm{r}=-0.843)$, tannin concentration $(\mathrm{r}=-0.782, \mathrm{r}=-$ 433 0.791) and not precipitable anthocyanin-derivative pigments $(\mathrm{MP}+\mathrm{SPP})(\mathrm{r}=-0.810, \mathrm{r}=-$ 
434 0.772). This result is well in line with models predicting accumulation of oxidation-

435 related aldehydes calculated by Bueno et al., (2018). In these models, the accumulation

436 of these compounds was negatively correlated to the content in different polyphenolic

437 compounds (anthocyanins and tannins), which were denominated aldehyde-reactive

438 polyphenols (ARPs). Thus, the lower levels of polyphenolic compounds acting as ARPs

439 found in wines elaborated with prematurely harvested grapes could explain the higher

440 OAVs values observed for both the isoaldehyde vector and phenylacetaldehyde

441 compound, and thus the appearance of oxidation nuances in these wines.

442 Sample BLA_4 presents a specific raisin aroma, which could be related to the presence 443 of higher levels of $\beta$-damascenone (San Juan et al., 2011). Interestingly, higher levels of

444 this norisoprenoid have been found in wines elaborated with dehydrated grapes in 445 comparison with fresh grapes (Bowen \& Reynolds, 2012; Genovese, Gambuti, 446 Piombino, \& Moio, 2007). This is well in accordance with studies that observed the 447 formation of $\beta$-damascenone in grapes during the on-vine dehydration process (Lan et 448 al., 2016). This could be the case of sample BLA_4, which was elaborated with the 449 ripest grapes and probably overripe.

\subsubsection{Astringency}

452 Astringency scores range between 0.53 and 3.6 (being 7 the maximum possible score) 453 and highly significant differences among wines $(\mathrm{F}=18.17 ; \mathrm{P}<0.00 \theta 1)$ are observed. 454 Table 6 shows 14 variables with potential to be involved in the formation of astringency 455 perception. All of them are significantly different $(\mathrm{P}<0.001)$ among the 21 wines 456 studied.

457 Astringency scores present significant $(\mathrm{p}<0.001)$ positive linear correlations with six out 458 of the 14 chemical variables studied, such as ethanol content and polyphenolic-related 
variables, including total polyphenol index, tannin activity and anthocyanin-derivative

460 pigments (such as monomeric and large polymeric pigments).

461 The role played by ethanol content in astringency perception is contradictory since there

462 are works that show a reduction of astringency with increasing ethanol content (Vidal et

463 al. 2004), which is attributed to a decrease of the strength of interaction between tannin

464 and protein in presence of increasing levels of ethanol (McRae et al. 2015). Contrary to

465 these reports, and in accordance with the presented results, there is a wide range of

466 papers (Watrelot et al. 2016, Sáenz-Navajas et al. 2010, 2012) that report significant

467 positive effects of ethanol on astringency perception. Thus, it cannot be ruled out that

468 certain astringent-related sensations are driven by other mechanisms different from

469 polyphenol-protein interactions.

470 Regarding anthocyanin-related compounds, both bleachable anthocyanins (or 471 monomeric anthocyanins, MP) and non-bleachable (or polymeric pigments, SPP+LPP)

472 present significant positive correlations with astringency (Table 6) $(\mathrm{r}=0.76 ; \mathrm{p}<0.00 \theta 1$

473 and $\mathrm{r}=0.79 ; \mathrm{p}<0.00 \theta 1$ respectively). To this concern, recent works suggest that certain

474 anthocyanins could be involved in the modulation of taste and/or mouthfeel properties

475 (Ferrer-Gallego et al., 2015; Paissoni et al., 2018; Sáenz-Navajas et al., 2017, 2018b).

476 Interestingly, tannin activity is highly correlated $(\mathrm{r}=0.91 ; \mathrm{p}<0 . \underline{01})$ with astringency, this

477 is the first time that this variable, that measures the affinity of tannins to a hydrophobic

478 surface (polystyrene divinylbenzene HPLC column), is related to sensory perception.

479 To this concern, same grape variety from similar origin and processed with the same

480 winemaking protocol, could have helped to establish such interesting linear relationship

481 between tannin activity and sensory astringency, in contradiction with other studies in

482 which not significant correlation could be found, which was attributed to a possible 
483 effect of aroma or even other non-volatile components on astringent perception

484 (Watrelot et al., 2016).

485

\section{Conclusions}

487 In the present work, the effect of Moristel grape maturity on wine sensory and chemical

488 composition was studied. This variety is shown as an interesting minor variety to be

489 cultivated under warm climates. Under the presented experimental winemaking protocol

490 Moristel grapes yielded wines with relatively low $\mathrm{pH}$ values, high red colour with

491 relatively low tannin activity, tannin and pigmented tannin concentrations that harvested

492 at optimal point is able to yield wines with fresh fruity aroma and a moderate

493 astringency. Interestingly, it was observed in the present work that Moristel grapes

494 prematurely harvested yield oxidation aroma nuances. This attribute is related to free

495 acetaldehyde, methional, phenylacetladehyde and isoaldehydes as well as to low levels

496 of aldehyde-reactive polyphenols (tannins, and anthocyanins that do not precipitate with

497 ovaoalbumin: MP and SPP). Contrary, grapes suffering on-vine dehydration, induce the

498 appearance development of raisin aroma in wines, which is suggested to be due to the

499 formation of $\beta$-damascenone already in grapes. Astringency is related to ethanol

500 content, tannin activity (measured as the interaction of tannins with a hydrophobic

501 surface) and the content in anthocyanin-derivative compounds.

502 At present, further studies are being carried out to find the grape precursors that yield

503 aldehydes in wines, this would help to control grape quality and define the optimal point

504 of harvest. Besides, it would be interesting to perform similar studies in other grape

505 varieties to elucidate if this tendency to generate oxidised wines with unripe grapes is a

506 general tendency or on the contrary is cultivar-dependent. 
509 Acknowledgements

510 Funded by the Spanish Ministry of Economy and Competitiveness (MINECO) (projects

511 RTC-2016-4935-2 and AGL-2017-87373-C3-3-R). M.P.S.N., I.A. and S.F.T

512 acknowledge the MINECO for her postdoctoral (Juan de la Cierva Incorporación 2015:

513 IJDC-2015-23444), his predoctoral fellowship (FPU-2016) and her predoctoral

514 fellowship (UR-CAR-2018), respectively. LAAE acknowledges the continuous support

515 of Diputación General de Aragón (T53) and European Social Fund. The authors want to

516 acknowledge Bodega Pirineos (Barbastro, Spain) for their support in winemaking.

References

519

520

521

522

523

524

525

526

527

528

529

530

531

532

533

534

535

536

537

538

539

540

541

542

543

544

545

Alegre, Y., Ferreira, V., \& Hernández-Orte, P. (2019). How does the addition of antioxidants and other sulfur compounds affect the metabolism of polyfunctional mercaptan precursors in model fermentations? Food Research International, $122,1-9$.

Abric, J. C. (2003). La recherche du noyau central et de la zone muette des représentations sociales. In J. C. Abric (Ed.), Méthodes d'étude des représentations sociales, (pp. 59-80). Ramonville Saint-Agne: Erès.

Ares, G., Bruzzone, F., Vidal, L., Cadena, R. S., Giménez, A., Pineau, B., Hunter, D. C., Paisley, A. G., \& Jaeger, S. R. (2014). Evaluation of a rating-based variant of check-all-that-apply questions: Rate-all-that-apply (RATA). Food Quality and Preference, 36, 87-95.

Bowen, A. J., \& Reynolds, A. G. (2012). Odor potency of aroma compounds in Riesling and Vidal blanc table wines and icewines by gas chromatography-olfactometrymass spectrometry. Journal of Agricultural and Food Chemistry, 60(11), 28742883.

Bueno, M., Zapata, J., \& Ferreira, V. (2014). Simultaneous determination of free and bonded forms of odor-active carbonyls in wine using a headspace solid phase microextraction strategy. Journal of Chromatography A, 1369, 33-42.

Bueno, M., Marrufo-Curtido, A., Carrascón, V., Fernández-Zurbano, P. Escudero, A., Ferreira, V. (2018). Formation and Accumulation of Acetaldehyde and Strecker aldehydes during Red Wine Oxidation. Frontiers in Chemistry, 6, 1-19.

Colonna, A. E., Adams, D. O., \& Noble, A. C. (2004). Comparison of procedures for reducing astringency carry-over effects in evaluation of red wines. Australian Journal of Grape and Wine Research, 10(1), 26-31.

Culleré, L., Cacho, J., \& Ferreira, V. (2007). An assessment of the role played by some oxidation-related aldehydes in wine aroma. Journal of Agricultural and Food Chemistry, 55(3), 876-881. 
Ferreira, V., Ortin, N., Escudero, A., Lopez, R., \& Cacho, J. (2002). Chemical characterization of the aroma of Grenache rose wines: Aroma extract dilution analysis, quantitative determination, and sensory reconstitution studies. Journal of Agricultural and Food Chemistry, 50(14), 4048-4054.

Ferreira, V., Sáenz-Navajas, M. P., \& de La Fuente, A. (2019). Wine aroma vectors and sensory attributes. In A. Reynolds (Ed.), Managing Wine Quality. Volume I: Viticulture and Wine Quality 2nd ed Woodhead Publishing 2020

Ferrer-Gallego, R., Soares, S., Mateus, N., Rivas-Gonzalo, J., Escribano-Bailon, M. T., \& de Freitas, V. (2015). New Anthocyanin-Human Salivary Protein Complexes. Langmuir, 31(30), 8392-8401.

Fournand, D., Vicens, A., Sidhoum, L., Souquet, J. M., Moutounet, M., \& Cheynier, V. (2006). Accumulation and extractability of grape skin tannins and anthocyanins at different advanced physiological stages. Journal of Agricultural and Food Chemistry, 54(19), 7331-7338.

García, J., Zheng, W., Balda, P., \& Martinez De Toda, F. (2017). Varietal differences in the sugar content of red grapes at the onset of anthocyanin synthesis. Vitis Journal of Grapevine Research, 56(1), 15-18.

Genovese, A., Gambuti, A., Piombino, P., \& Moio, L. (2007). Sensory properties and aroma compounds of sweet Fiano wine. Food Chemistry, 103(4), 1228-1236.

Gil, M., Kontoudakis, N., González, E., Esteruelas, M., Fort, F., Canals, J. M., \& Zamora, F. (2012). Influence of Grape maturity and maceration length on color, polyphenolic composition, and polysaccharide content of Cabernet Sauvignon and Tempranillo Wines. Journal of Agricultural and Food Chemistry, 60(32), 7988-8001.

Gonzalo-Diago, A., Dizy, M., \& Fernandez-Zurbano, P. (2013). Taste and Mouthfeel Properties of Red Wines Proanthocyanidins and Their Relation to the Chemical Composition. Journal of Agricultural and Food Chemistry, 61(37), 8861-8870.

Harbertson, J., Picciotto, E., \& Adams, D. (2003). Measurement of polymeric pigments in grape berry extracts and wines using a protein precipitation assay combined with bisulfite bleaching. American Journal of Enology and Viticulture, 54(4), 301-306.

Labarbe, B., Cheynier, V., Brossaud, F., Souquet, J. M., \& Moutounet, M. (1999). Quantitative fractionation of grape proanthocyanidins according to their degree of polymerization. Journal of Agricultural and Food Chemistry, 47(7), 27192723.

Lan, Y. B., Qian, X., Yang, Z. J., Xiang, X. F., Yang, W. X., Liu, T., Zhu, B. Q., Pan, Q. H., \& Duan, C. Q. (2016). Striking changes in volatile profiles at sub-zero temperatures during over-ripening of 'Beibinghong' grapes in Northeastern China. Food Chemistry, 212, 172-182.

Lopez, R., Aznar, M., Cacho, J., \& Ferreira, V. (2002). Determination of minor and trace volatile compounds in wine by solid-phase extraction and gas chromatography with mass spectrometric detection. Journal of Chromatography A, 966(1-2), 167-177.

McRae, J. M., Ziora, Z. M., Kassara, S., Cooper, M. A., \& Smith, P. A. (2015). Ethanol concentration influences the mechanisms of wine tannin interactions with poly(l -proline) in model wine. Journal of Agricultural and Food Chemistry, 63(17), 4345-4352.

Niimi, J., Boss, P. K., Jeffery, D., \& Bastian, S. E. P. (2017). Linking Sensory Properties and Chemical Composition of $\langle\mathrm{em}>$ Vitis vinifera $</ \mathrm{em}>\mathrm{cv}$. Cabernet 

Viticulture, 68(3), 357-368.

Ortega, C., Lopez, R., Cacho, J., \& Ferreira, V. (2001). Fast analysis of important wine volatile compounds Development and validation of a new method based on gas chromatographic-flame ionisation detection analysis of dichloromethane microextracts. Journal of Chromatography A, 923(1-2), 205-214.

Paissoni, M. A., Waffo-Teguo, P., Ma, W., Jourdes, M., Rolle, L., \& Teissedre, P. L. (2018). Chemical and sensorial investigation of in-mouth sensory properties of grape anthocyanins. Scientific Reports, 8(1).

Parker, M., Capone, D. L., Francis, I. L., \& Herderich, M. J. (2018). Aroma Precursors in Grapes and Wine: Flavor Release during Wine Production and Consumption. Journal of Agricultural and Food Chemistry, 66(10), 2281-2286.

Pérez-Magariño, S., \& González-San José, M. L. (2006). Polyphenols and colour variability of red wines made from grapes harvested at different ripeness grade. Food Chemistry, 96(2), 197-208.

Pineau, B., Barbe, J. C., Leeuwen, C. V., \& Dubourdieu, D. (2009). Examples of perceptive interactions involved in specific "Red-" and "Black-berry" aromas in red wines. Journal of Agricultural and Food Chemistry, 57(9), 3702-3708.

Revelette, M. R., Barak, J. A., \& Kennedy, J. A. (2014). High-performance liquid chromatography determination of red wine tannin stickiness. Journal of Agricultural and Food Chemistry, 62(28), 6626-6631.

Robinson, J., Harding, J., \& Vouillamoz, J. (2012). Wine Grapes. A complete guide to 1,368 vine varieties, including their origins and flavours.

Sáenz-Navajas, M. P., Arias, I., Ferrero-del-Teso, S., Fernández-Zurbano, P., Escudero, A., \& Ferreira, V. (2018). Chemo-sensory approach for the identification of chemical compounds driving green character in red wines. Food Research International, 109, 138-148.

Sáenz-Navajas, M. P., Avizcuri, J. M., Ballester, J., Fernández-Zurbano, P., Ferreira, V., Peyron, D., \& Valentin, D. (2015). Sensory-active compounds influencing wine experts' and consumers' perception of red wine intrinsic quality. LWT Food Science and Technology, 60, 400-411.

Sáenz-Navajas, M. P., Avizcuri, J. M., Ferreira, V., \& Fernández-Zurbano, P. (2012). Insights on the chemical basis of the astringency of Spanish red wines. Food Chemistry, 134(3), 1484-1493.

Sáenz-Navajas, M. P., Avizcuri, J. M., Ferrero-del-Teso, S., Valentin, D., Ferreira, V., \& Fernández-Zurbano, P. (2017). Chemo-sensory characterization of fractions driving different mouthfeel properties in red wines. Food Research International, 94, 54-64.

Saenz-Navajas, M. P., Fernandez-Zurbano, P., Tao, Y. S., Dizy, M., \& Ferreira, V. (2010). Relationship between nonvolatile composition and sensory properties of premium Spanish red wines and their correlation to quality perception. Journal of Agricultural and Food Chemistry, 58(23), 12407-12416.

Sáenz-Navajas, M. P., Gonzalez-Hernandez, M., Campo, E., Fernández-Zurbano, P., \& Ferreira, V. (2012). Orthonasal aroma characteristics of Spanish red wines from different price categories and their relationship to expert quality judgements. Australian Journal of Grape and Wine Research, 18(3), 268-279.

Sáenz-Navajas, M. P., Henschen, C., Cantu, A., Watrelot, A. A., \& Waterhouse, A. L. (2018). Understanding microoxygenation: Effect of viable yeasts and sulfur dioxide levels on the sensory properties of a Merlot red wine. Food Research International, 108, 505-515. 
645 San Juan, F., Ferreira, V., Cacho, J., \& Escudero, A. (2011). Quality and aromatic 646 sensory descriptors (mainly fresh and dried fruit character) of Spanish red wines 647 can be predicted from their aroma-active chemical composition. Journal of Agricultural and Food Chemistry, 59(14), 7916-7924.

650

651

652

653

654

655

656

657

658

659

660

661

Soto Vázquez, E., Río Segade, S., \& Orriols Fernández, I. (2010). Effect of the winemaking technique on phenolic composition and chromatic characteristics in young red wines. European Food Research and Technology, 231(5), 789-802.

Watrelot, A. A., Byrnes, N. K., Heymann, H., \& Kennedy, J. A. (2016). Understanding the Relationship between Red Wine Matrix, Tannin Activity, and Sensory Properties. Journal of Agricultural and Food Chemistry, 64(47), 9116-9123.

Wen, Y., Ontañon, I., Ferreira, V., \& Lopez, R. (2018). Determination of ppq-levels of alkylmethoxypyrazines in wine by stirbar sorptive extraction combined with multidimensional gas chromatography-mass spectrometry. Food Chemistry, 255, 235-241.

Yacco, R. S., Watrelot, A. A., \& Kennedy, J. A. (2016). Red Wine Tannin StructureActivity Relationships during Fermentation and Maceration. Journal of

662 


\section{Figure captions}

664 Figure 1. Sensory attributes (expressed as the average of three tanks, error bars are the

665

666

667

668

669

670

671

672 standar deviation among the three tanks) that present significant effects of grape maturity in wines elaborated with grapes of a) Block $A$ harvested at four different points (BLA_1, BLA_2, BLA_3, BLA_4) and Block B harvested at four different points (BLB_1, BLB_2, BLB_4).

Figure 2. Principal component analysis plot calculated with the 7 different wines elaborated, chemical aroma parameters as active variables and sensory attributes as supplementary variables. 
Table 1. Aroma vectors built by grouping volatile compounds with similar chemical and aroma description according to Ferreira, Sáenz-Navajas, and de La Fuente (2019).

\begin{tabular}{|c|c|c|}
\hline Vector & Compounds in the vector & Aroma description \\
\hline Acetate vector & isobutyl acetate, butyl acetate & Fruity, pear \\
\hline Acetic vector & ethyl acetate, acetic acid & Glue, vinegar \\
\hline Branched acid vector & 3-methylbutyric, 2-methylpropanoic acids & Cheese, sweaty \\
\hline & ethyl proponoate, ethyl butyrate, ethyl & \\
\hline Ethyl ester vector & $\begin{array}{l}\text { decanoate, ethyl isobutyrate, ethyl 2- } \\
\text { methylbutyrate, ethyl isovalerate, ethyl } \\
\text { lactate, diethyl succinate }\end{array}$ & Fruity, apple, strawberry \\
\hline Ethyl phenol vector & 4-ethylguaicol, 4-ethylphenol & Animal, leather \\
\hline Isoaldehyde vector & $\begin{array}{l}\text { isobutanal, 2-methylbutanal, 3- } \\
\text { methylbutanal }\end{array}$ & Malty, yeasty \\
\hline Higher alcohol vector & $\begin{array}{l}\text { isobutanol, isoamyl alcohol, } \\
\beta \text {-phenylethanol, 1-butanol, methionol, } \\
\text { benzylic alcohol, 1-penten-3-ol, 1-hexanol, } \\
\text { z-3-hexenol, t-2-hexenol, t-3-hexenol, 1- } \\
\text { octen-3-ol }\end{array}$ & Harsh, spirit, solvent \\
\hline$\gamma$-Lactone vector & $\nu$-nonalactone, $\gamma$-butyrolactone & Peachy \\
\hline Linear fatty acid vector & butyric, hexanoic, octanoic, decanoic acids & Cheese, soapy \\
\hline Methoxyphenol vector & $\begin{array}{l}\text { guaiacol, eugenol, isoeugenol, 4- } \\
\text { vinylguaiacol, 2,6-dimethoxyphenol, 4- } \\
\text { allyl-2,6-dimethoxyphenol, 4-vinylphenol, } \\
\text { o-cresol, m-cresol }\end{array}$ & Clove, smoky \\
\hline Methoxypyrazine vector & $\begin{array}{l}\text { 3-isopropil-2-methoxypyrazine (IPMP), 3- } \\
\text { isobuthyl-2-methoxypyrazine (IBMP) }\end{array}$ & Green, earthy, green pepper \\
\hline Terpenol vector & geraniol, $\beta$-citronellol, $\alpha$-terpineol, linalool & $\begin{array}{l}\text { Jasmine, muscat, orange } \\
\text { blossom }\end{array}$ \\
\hline Vanilla vector & $\begin{array}{l}\text { vanillin, acetovanillone, ethyl vanillate, } \\
\text { methyl vanillate }\end{array}$ & Vanilla, nutmeg \\
\hline
\end{tabular}


Table 2. Conventional oenological parameters of wines and grapes (sugar content) expressed as the average (among replicated tanks) \pm standard deviation. Different letters within the same block (BLA or BLB) indicate significant differences $(\mathrm{P}<0.05$ according to pairwise Fischer test) among the maturity points (BLA1-BLA4 or BLB1-BLB3).

\begin{tabular}{|c|c|c|c|c|c|c|c|c|c|}
\hline & \multirow{2}{*}{$\begin{array}{c}\text { GRAPES } \\
\text { sugar } \\
\text { content } \\
\left(\mathrm{g} \mathrm{L}^{-1}\right) \\
\end{array}$} & \multicolumn{8}{|c|}{ WINES } \\
\hline & & $\mathrm{pH}$ & $\begin{array}{l}\text { volatile acidity } \\
\text { (g L } \mathrm{L}^{-1} \text { acetic acid) }\end{array}$ & $\begin{array}{c}\text { titratable acidity } \\
\text { (g L }{ }^{-1} \text { tartaric } \\
\text { acid) }\end{array}$ & $\begin{array}{l}\text { reducing sugars } \\
\qquad\left(\mathrm{g} \mathrm{L}^{-1}\right)\end{array}$ & $\begin{array}{l}\text { malic acid } \\
\qquad\left(\mathrm{g} \mathrm{L}^{-1}\right)\end{array}$ & $\begin{array}{l}\text { lactic acid } \\
\qquad\left(\mathrm{g} \mathrm{L}^{-1}\right)\end{array}$ & $\begin{array}{l}\text { ethanol } \\
\text { content } \\
\text { (\%.v/v) }\end{array}$ & $\begin{array}{l}\text { TPI }_{-}^{*} \\
\text { (a.u.) }\end{array}$ \\
\hline BLA_1 & $251 \pm 3 b$ & $3.2 \pm 0.0$ & $0.5 \pm 0.0$ & $6.7 \pm 0.0 \mathrm{a}$ & $2.0 \pm 0.1 \mathrm{c}$ & $0.6 \pm 0.0 \mathrm{~b}$ & $0.2 \pm 0.1$ & $14.8 \pm 0.2 b$ & $45.2 \pm 0.0 b$ \\
\hline BLA_2 & $254 \pm 5 b$ & $3.3 \pm 0.0$ & $0.5 \pm 0.0$ & $6.0 \pm 0.0 \mathrm{~b}$ & $2.3 \pm 0.0 \mathrm{~b}$ & $0.3 \pm 0.0 c$ & $0.2 \pm 0.1$ & $14.9 \pm 0.2 b$ & $45.6 \pm 0.0 b$ \\
\hline BLA_3 & $250 \pm 11 b$ & $3.3 \pm 0.0$ & $0.4 \pm 0.0$ & $6.1 \pm 0.0 b$ & $2.6 \pm 0.1 a$ & $0.4 \pm 0.0 c$ & $0.3 \pm 0.0$ & $14.4 \pm 0.3 b$ & $43.8 \pm 0.1 b$ \\
\hline BLA_4 & $267 \pm 3 a$ & $3.3 \pm 0.0$ & $0.4 \pm 0.0$ & $5.8 \pm 0.0 c$ & $2.5 \pm 0.0 \mathrm{a}$ & $0.8 \pm 0.0 a$ & $0.1 \pm 0.0$ & $15.8 \pm 0.0 \mathrm{a}$ & $53.0 \pm 0.0 \mathrm{a}$ \\
\hline BLB_1 & $224 \pm 9 b$ & $3.2 \pm 0.1$ & $0.5 \pm 0.0$ & $6.4 \pm 0.1 a$ & $1.6 \pm 0.0 \mathrm{~b}$ & $0.3 \pm 0.1 b$ & $0.5 \pm 0.0$ & $12.4 \pm 0.2 b$ & $22.1 \pm 1.7 \mathrm{~b}$ \\
\hline BLB_2 & $227 \pm 12 b$ & $3.2 \pm 0.0$ & $0.3 \pm 0.0$ & $6.0 \pm 0.0 b$ & $1.6 \pm 0.0 \mathrm{~b}$ & $0.5 \pm 0.1 a$ & $0.5 \pm 0.1$ & $12.7 \pm 0.3 b$ & $24.2 \pm 1.0 \mathrm{a}$ \\
\hline BLB_4 & $250 \pm 6 a$ & $3.2 \pm 0.0$ & $0.4 \pm 0.0$ & $6.0 \pm 0.2 b$ & $1.9 \pm 0.0 a$ & $0.3 \pm 0.0 \mathrm{~b}$ & $0.5 \pm 0.0$ & $13.7 \pm 0.2 \mathrm{a}$ & $25.7 \pm 0.6 a$ \\
\hline
\end{tabular}


| Table 3. Chemical characterisation of polyphenolic composition and colour coordinates $\left(a_{10}{ }_{1}^{*}, b_{10}{ }_{10}^{*} L^{*}\right)$ in wines expressed as the average (among replicated tanks) \pm standard deviation. Different letters within the same block (BLA or BLB) indicate significant differences ( $P<0.05$ according to pairwise Fischer test) among the maturity points (BLA1-BLA4 or BLB1-BLB4). Numbers marked in bold are the highest values within a block

\begin{tabular}{|c|c|c|c|c|c|c|c|}
\hline & $\begin{array}{c}\text { tannin activity } \\
\left(-J \mathrm{~mol}^{-1}\right)\end{array}$ & $\begin{array}{l}\text { tannin concentration } \\
\qquad\left(\mathrm{mg} \mathrm{L}^{-1}\right)\end{array}$ & $\begin{array}{l}\text { pigmented tannins } \\
\qquad\left(\mathrm{mg} \mathrm{L}^{-1}\right)\end{array}$ & $m \mathrm{mp}^{\underline{1}}$ & $a^{*}$ & $\mathbf{b}^{*}$ & $L^{*}$ \\
\hline BLA_2 & $2689 \pm 96 a$ & $3051 \pm 67 c$ & $841 \pm 120 b$ & $1.3 \pm 0.0 c$ & $56.6 \pm 0.1 c$ & $8.8 \pm 0.2 b$ & $45.0 \pm 0.1 b$ \\
\hline BLA_4 & $2673 \pm 32 a$ & $3472 \pm 40 \mathrm{~b}$ & $854 \pm 80 \mathrm{~b}$ & $1.9 \pm 0.0 \mathrm{~b}$ & $57.8 \pm 0.1 b$ & $12.5 \pm 0.4 a$ & $43.9 \pm 0.1 c$ \\
\hline BLB_1 & $1044 \pm 47 a$ & $2071 \pm 199$ & $618 \pm 79$ & $1.6 \pm 0.2$ & $42.2 \pm 0.6 a$ & $0.4 \pm 0.1$ & $64.3 \pm 0.0 b$ \\
\hline BLB_2 & $933 \pm 90 b$ & $1993 \pm 163$ & $646 \pm 69$ & $1.7 \pm 0.2$ & $43.6 \pm 2.0 \mathrm{~b}$ & $1.4 \pm 0.9$ & $63.9 \pm 2.3 b$ \\
\hline BLB_4 & $854 \pm 61 c$ & $2066 \pm 111$ & $687 \pm 51$ & $1.8 \pm 0.2$ & $36.7 \pm 0.6 a$ & $0.4 \pm 0.4$ & $70.4 \pm 0.4 a$ \\
\hline
\end{tabular}

$\underline{{ }^{1} \text { mean deagree of polymerisation }}$ 
Table 4. Limit of detection (LOD), odour thresholds, concentration ranges and median values of volatiles found in the set of the 21 wines (all expressed in micrograms per litre). Maximum to minimum odour activity value rate (OAV MAX $\angle O A V_{M I N}$. Compounds found in at least one wine at concentrations above their sensory threshold are marked in bold. Based on sensory impact of compounds, part of them are grouped into aroma vectors (they act in a concerted way), and other 11 are individually presented.

\begin{tabular}{|c|c|c|c|c|c|}
\hline compounds & LOD & odour threshold $^{\mathrm{a}}$ & concentration range & median & OAV $V_{\text {MAX }} /$ OAV $_{\text {MIN }}$ \\
\hline$\beta$-ionone & 0.33 & $0.09[5]$ & $0.393-0.752$ & 0.499 & 1.91 \\
\hline diacetyl & 1.59 & $100[3]$ & 244-12245 & 1996 & 50.1 \\
\hline acetaldehyde (free) & 115 & $500[3]$ & $<$ LD-5437 & 815 & 47.3 \\
\hline$\beta$-damascenone & 0.187 & $0.05[3]$ & $<$ LD-2.69 & 0.682 & 14.4 \\
\hline isoamyl acetate & 18 & $30[3]$ & $80.9-301$ & 163 & 3.72 \\
\hline phenylacetaldehyde & 1.67 & $1[15]$ & $6.68-22$ & 13 & 3.3 \\
\hline$z$-3-hexenal & 0.059 & $0.12[22]$ & 15.1-24.9 & 18.3 & 1.65 \\
\hline ethyl dihydrocinnamate & 0.026 & $1.6[5]$ & $<$ LD-0.491 & 0.375 & 1.53 \\
\hline phenylethyl acetate & 0.019 & $250[3]$ & $2.51-8.35$ & 4.88 & 0.167 \\
\hline$t$-whiskylactone & 0.09 & $790[2]$ & $<$ LD-0.796 & 0 & 0.005 \\
\hline vectprs & LOD & Odour threshold $^{\mathrm{a}}$ & Concentration Range & Median & $O A V_{\text {MAX }} /$ OAV $_{\text {MIN }}$ \\
\hline \multicolumn{6}{|l|}{ acetate vector } \\
\hline butyl acetate & 0.167 & $1800[2]$ & $1.8-15.9$ & 3.39 & 0.044 \\
\hline isobutyl acetate & 0.158 & $1600[1]$ & $5.42-16$ & 6.73 & 0.05 \\
\hline \multicolumn{6}{|l|}{ acetic vector } \\
\hline acetic acid & 240 & $300000[3]$ & $270496-746363$ & 449652 & 2.76 \\
\hline ethyl acetate & 10 & $12300[4]$ & $1062-81907$ & 49833 & 33.3 \\
\hline \multicolumn{6}{|l|}{ branched acids vector } \\
\hline isobutyric acid & 101 & $2300[6]$ & 2029-3004 & 2574 & 1.48 \\
\hline isovalerianic acid & 28 & $33[5]$ & $60-3731$ & 2211 & 62.2 \\
\hline \multicolumn{6}{|l|}{ ethyl ester vector } \\
\hline ethyl propanoate & 50 & $5500[9]$ & $<\mathrm{LD}-228$ & 0 & 0.207 \\
\hline ethyl butyrate & 26.3 & $125[9]$ & 46-157 & 102 & 3.42 \\
\hline ethyl hexanoate & 34.2 & $62[9]$ & $145-490$ & 277 & 3.38 \\
\hline ethyl octanoate & 12 & $580[2]$ & $50.9-173$ & 120 & 1.49 \\
\hline ethyl decanoate & 17.2 & $200[5]$ & $<$ LD-409 & 33.6 & 10.2 \\
\hline ethyl isobutyrate & 0.495 & $15[5]$ & $79.9-164$ & 106 & 2.06 \\
\hline ethyl 2-methylbutyrate & 0.33 & $18[5]$ & $10.3-20$ & 16.6 & 1.94 \\
\hline ethyl isovalerate & 0.33 & $3[5]$ & 13.7-61.4 & 20.1 & 4.48 \\
\hline ethyl lactate & 100 & $154000[2]$ & $10675-69951$ & 33465 & 2.27 \\
\hline diethyl succinate & 3 & $200000[2]$ & 1137-8994 & 7714 & 0.225 \\
\hline \multicolumn{6}{|l|}{ ethylphenol vector } \\
\hline 4-ethylguaiacol & 0.018 & $33[5]$ & $<$ LD-0.289 & 0.09 & 0.044 \\
\hline 4-ethylphenol & 0.023 & $35[9]$ & $<$ LD-1.5 & 0.175 & 0.215 \\
\hline \multicolumn{6}{|l|}{ isoaldehyde vector } \\
\hline isobutanal & 0.495 & $6[15]$ & $16.5-43.4$ & 30.8 & 2.63 \\
\hline 2-methylbutanal & 0.176 & $16[15]$ & $5.97-14.9$ & 9.45 & 2.5 \\
\hline 3-methylbutanal & 0.206 & $4.6[15]$ & $6.85-55.4$ & 21.2 & 8.1 \\
\hline \multicolumn{6}{|l|}{ higher alcohol vector } \\
\hline benzylic alcohol & 10 & $200000[7]$ & $44.1-468$ & 199 & 0.012 \\
\hline 1-butanol & 2 & $150000[2]$ & $876-1885$ & 1144 & 0.063 \\
\hline 1-hexanol & 14 & $8000[3]$ & $2556-3348$ & 2921 & 1.31 \\
\hline $\mathrm{t}$-2-hexenol & 0.739 & $15000[21]$ & $<$ LD-16.6 & 3.02 & 0.006 \\
\hline t-3-hexenol & 0.166 & $1000[20]$ & $33.8-86.1$ & 59.7 & 0.43 \\
\hline z-3-hexenol & 12.2 & $400[3]$ & $27.9-168$ & 48.4 & 2.11 \\
\hline isoamyl alcohol & 19 & $30000[3]$ & 219088-289686 & 259247 & 1.32 \\
\hline isobutanol & 24.3 & $40000[3]$ & $28890-40186$ & 32461 & 1.39 \\
\hline methionol & 26 & $1000[5]$ & $169-3882$ & 993 & 19.4 \\
\hline 1-octen-3-ol & 3.85 & $40[18]$ & $8.73-35.2$ & 16.4 & 4.03 \\
\hline 1-penten-3-ol & 7.81 & $400[19]$ & $<$ LD-294 & 97.2 & 3.68 \\
\hline$\beta$-phenylethanol & 5 & $14000[5]$ & $2946-43218$ & 32360 & 14.7 \\
\hline \multicolumn{6}{|l|}{$\gamma$-lactone vector } \\
\hline$\gamma$-butyrolactone & 18.3 & $35000[12]$ & $1071-17501$ & 10821 & 2.5 \\
\hline$\gamma$-nonalactone & 0.064 & $25[14]$ & $9.93-25.1$ & 17.1 & 2.52 \\
\hline \multicolumn{6}{|l|}{ linear fatty acid vector } \\
\hline butyric acid & 100 & $173[5]$ & $162-1170$ & 678 & 7.24 \\
\hline hexanoic acid & 10 & $420[5]$ & $177-1992$ & 1546 & 11.3 \\
\hline octanoic acid & 10 & $500[5]$ & $729-1561$ & 975 & 2.14 \\
\hline decanoic acid & 27 & $1000[5]$ & $<$ LD-909 & 474 & 4.55 \\
\hline \multicolumn{6}{|l|}{ methoxyphenol vector } \\
\hline guaiacol & 0.05 & $9.5[5]$ & $<$ LD-21.5 & 5.67 & 11.3 \\
\hline eugenol & 0.019 & $6[5]$ & $1.23-2.99$ & 1.61 & 2.43 \\
\hline 4-vinylguaiacol & 0.039 & $40[3]$ & $5.75-24.7$ & 11 & 3.09 \\
\hline isoeugenol & 0.073 & $6[12]$ & $1.04-14.3$ & 3.46 & 11.9 \\
\hline 2,6-dimethoxyphenol & 0.048 & $570[10]$ & $4.16-23.9$ & 8.65 & 0.21 \\
\hline 4-alyl-2,6-dimethoxyphenol & 0.33 & $1200[6]$ & $1.78-6.15$ & 2.96 & 0.026 \\
\hline o-cresol & 0.33 & $31[2]$ & $<$ LD-1.05 & 0.828 & 0.17 \\
\hline$m$-cresol & 0.003 & $68[11]$ & $<$ LD-0.68 & 0.078 & 0.05 \\
\hline $\begin{array}{l}\text { 4-vinylphenol } \\
\text { methoxypyrazine Vector }\end{array}$ & 0.055 & $180[13]$ & $6.03-52.4$ & 14.1 & 1.46 \\
\hline 2-isopropyl-3-methoxypyrazine (IPMP) & 0.00007 & $0.0003[17]$ & $<$ LD-0.00138 & 0.00007 & 19.6 \\
\hline 2-isobutyl-3-methoxypyrazine (IBMP) & 0.00002 & $0.002[17]$ & $0.00087-0.00222$ & 0.00157 & 2.56 \\
\hline
\end{tabular}




\begin{tabular}{|c|c|c|c|c|c|}
\hline vectors & LOD & Odour threshold ${ }^{\text {a }}$ & Concentration Range & Median & $O A V_{\text {MAX }} / O A V_{\text {MIN }}$ \\
\hline \multicolumn{6}{|l|}{ terpenol vector } \\
\hline linalool & 0.045 & $25[5]$ & $2.37-5.05$ & 3.37 & 1.01 \\
\hline$\alpha$-terpineol & 0.048 & $250[5]$ & $0.853-1.91$ & 1.46 & 0.038 \\
\hline$\beta$-citronelol & 0.779 & $100[2]$ & $<$ LD-4.92 & 2.69 & 0.246 \\
\hline geraniol & 0.33 & $20[12]$ & $1.38-5.41$ & 3.87 & 1.35 \\
\hline \multicolumn{6}{|l|}{ vani|llin vector } \\
\hline vanillin & 0.076 & $995[12]$ & $3.44-15$ & 6.64 & 0.075 \\
\hline methyl vanillate & 0.041 & $3000[10]$ & $2.41-5.54$ & 3.52 & 0.009 \\
\hline ethyl vanillate & 0.059 & $990[10]$ & $67.3-256$ & 133 & 1.29 \\
\hline acetovanillone & 0.136 & $1000[12]$ & $32-78.1$ & 53 & 0.391 \\
\hline
\end{tabular}

${ }^{a}$ Odour thresholds. Reference in which the odour threshold value has been calculated is given in brackets. [1] Ferreira et al. (2002). [2] Etievant et al. (1991). [3] Guth (1997). [4] Escudero et al. (2004). [5] Ferreira et al. (2000). [6] Gemert (2003). [7] Aznar et al. (2003). [8] Peinado et al. (2004). [9] San Juan et al. (2012). [10] Lopez et al. (2002). [11] Ferreira et al. (2009). [12] Escudero et al. (2007). [13] Boidron et al. (1988). [14] Gemert (2003). [15] Cullere et.al (2007). [16] Cullere et.al (2016). [17] Hjelmeland et.al (2016). [18] Boutou et Chatonnet (2007). [19] Buttery et.al (1971). [20] Fariña et.al (2014). [21] Darici et.al (2014). [22 Sellami et.al (2018).

${ }^{\mathrm{b}}$ For $\mathrm{OAV}$ minimum $<0.2$, this value is considered for calculating the quotient. 
Table 5. Individual aroma compounds and vectors with possible sensory impact (Odour Activity Values, $\mathrm{OAV}>1)$, with ability to differentiate $\left(\mathrm{OAV}_{\mathrm{Max}} / \mathrm{OAV} \mathrm{V}_{\text {Min }}>2\right)$ and significantly different among the 21 studied wines. Maximum and minimum OAVs found in the set of wines. Significance (P-value): $* * * * P<0.001$; $* * * \mathrm{P}<0.01 ; * * \mathrm{P}<0.05,{ }^{*} \mathrm{P}<0.1$ ) of the ANOVA (wines as fixed factors).

\begin{tabular}{lcccc}
\hline compounds & $\mathrm{OAV}_{\text {Max }}$ & $\mathrm{OAV}_{\text {Min }}$ & $\mathrm{OAV}_{\text {Max }} / \mathrm{OAV}_{\text {Min }}$ & $\begin{array}{c}\text { significance } \\
\text { P-value }^{-}\end{array}$ \\
\hline acetaldehyde (free) & 10.9 & 0.23 & 47.3 & $* *$ \\
branched fatty acid vector & 114 & 2.96 & 38.7 & $* * * *$ \\
B-damascenone & 53.8 & 3.73 & 14.4 & $* * * *$ \\
methoxypyrazine vector & 5.61 & 0.666 & 8.42 & $* * * *$ \\
methoxyphenol vector & 5.4 & 0.853 & 6.33 & $* * * *$ \\
acetic vector & 8.19 & 1.81 & 4.53 & $* * * *$ \\
isoaldehyde vector & 19.5 & 5.17 & 3.77 & $* * * *$ \\
isoamyl acetate & 10 & 2.7 & 3.72 & $* *$ \\
linear fatty acid vector & 14 & 3.97 & 3.53 & $* * * *$ \\
phenylacetaldehyde & 22 & 6.68 & 3.30 & $* * *$ \\
-lactone vector & 1.34 & 0.466 & 2.87 & $* * * *$ \\
methional & 55.8 & 22.5 & 2.49 & $*$ \\
ethyl ester vector & 36.6 & 15.8 & 2.32 & $* * * *$ \\
\hline
\end{tabular}


Table 6. Conventional parameters and phenolic-related parameters analysed in the 21 wine samples of the study. Maximum, minimum, median, quotient of maximal and minimal level, and Pearson correlation coefficients $(r)$ between sensory astringency and chemical variables (significance: ${ }^{*} P<0.01$ ). Chemical variables with significant lineal correlation with astringency are marked in bold.

\begin{tabular}{lccccc}
\hline & max & $\min$ & median & max/min & r (astringency) \\
\hline $\mathrm{pH}$ & 3.3 & 3.1 & 3.3 & 1.1 & 0.25 \\
titratable acidity (TA) (g/L) & 6.8 & 5.8 & 6.1 & 1.2 & 0.22 \\
ethanol content (\% v/v) & $\mathbf{1 5 . 8}$ & $\mathbf{1 1 . 8}$ & $\mathbf{1 3 . 4}$ & $\mathbf{1 . 3 4}$ & $\mathbf{0 . 6 9 *}$ \\
colour intensity (CI) (a.u.) & $\mathbf{1 4 . 0}$ & $\mathbf{4 . 3 0}$ & $\mathbf{6 . 4 0}$ & $\mathbf{3 . 2 6}$ & $\mathbf{0 . 7 9 *}$ \\
total polyphenol index (TPI) (a.u.) & $\mathbf{5 3 . 0}$ & $\mathbf{2 1 . 0}$ & $\mathbf{2 5 . 5}$ & $\mathbf{2 . 5 2}$ & $\mathbf{0 . 7 5 *}$ \\
tannin activity (TA) (-J/mol) & $\mathbf{2 7 6 5}$ & $\mathbf{7 3 9}$ & $\mathbf{1 0 0 7}$ & $\mathbf{3 . 7 4}$ & $\mathbf{0 . 8 3}$ \\
tannin concentration (TC) (mg/L) & 4193 & 1794 & 2192 & 2.34 & 0.57 \\
monomeric pigments (MP) (a.u.) & $\mathbf{0 . 9 6}$ & $\mathbf{0 . 2 6}$ & $\mathbf{0 . 4 2}$ & $\mathbf{3 . 7}$ & $\mathbf{0 . 7 6}$ \\
small and large polymeric pigments (SPP+LPP) (a.u.) & $\mathbf{0 . 6 0}$ & $\mathbf{0 . 1 7}$ & $\mathbf{0 . 2 5}$ & $\mathbf{4 . 1}$ & $\mathbf{0 . 7 9 *}$ \\
mean degree of polymerisation (mDP) & 2.9 & 1.2 & 1.7 & 2.3 & -0.17 \\
\% of procyanidins in tannins (\%PC) & 78.0 & 40.9 & 67.2 & 1.90 & -0.27 \\
\% of galloylated tannins (\%G) & 2.33 & 0.639 & 1.21 & 3.64 & 0.39 \\
\% of prodelphinidins in tannins (\%PD) & 10.6 & 2.65 & 6.00 & 3.98 & -0.22 \\
\% of malvidin in tannins (\%M-T) & 53.4 & 9.14 & 25.3 & 5.85 & 0.27 \\
\hline
\end{tabular}


a)

Block A (BLA)

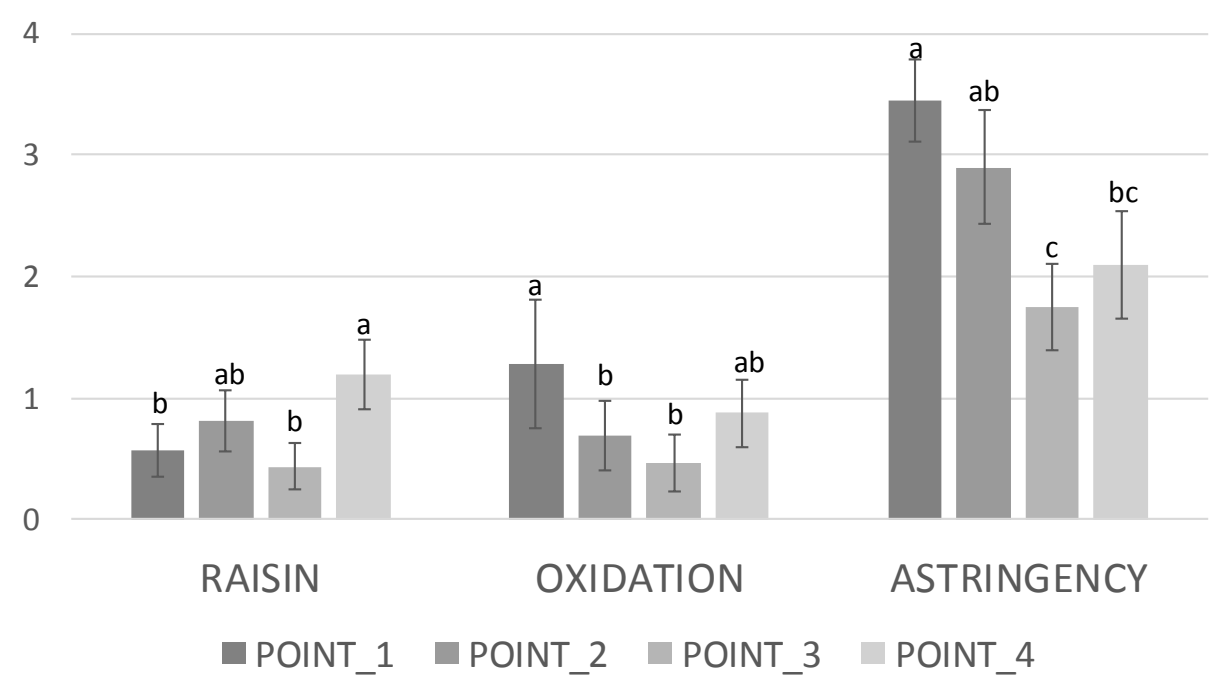

b)

Block B (BLB)

3

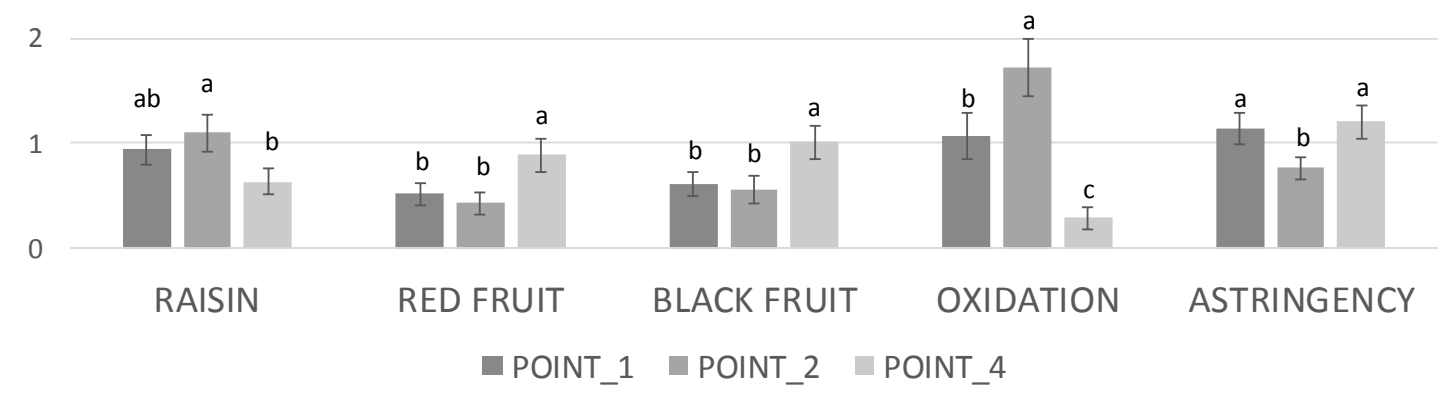

Figure 1 


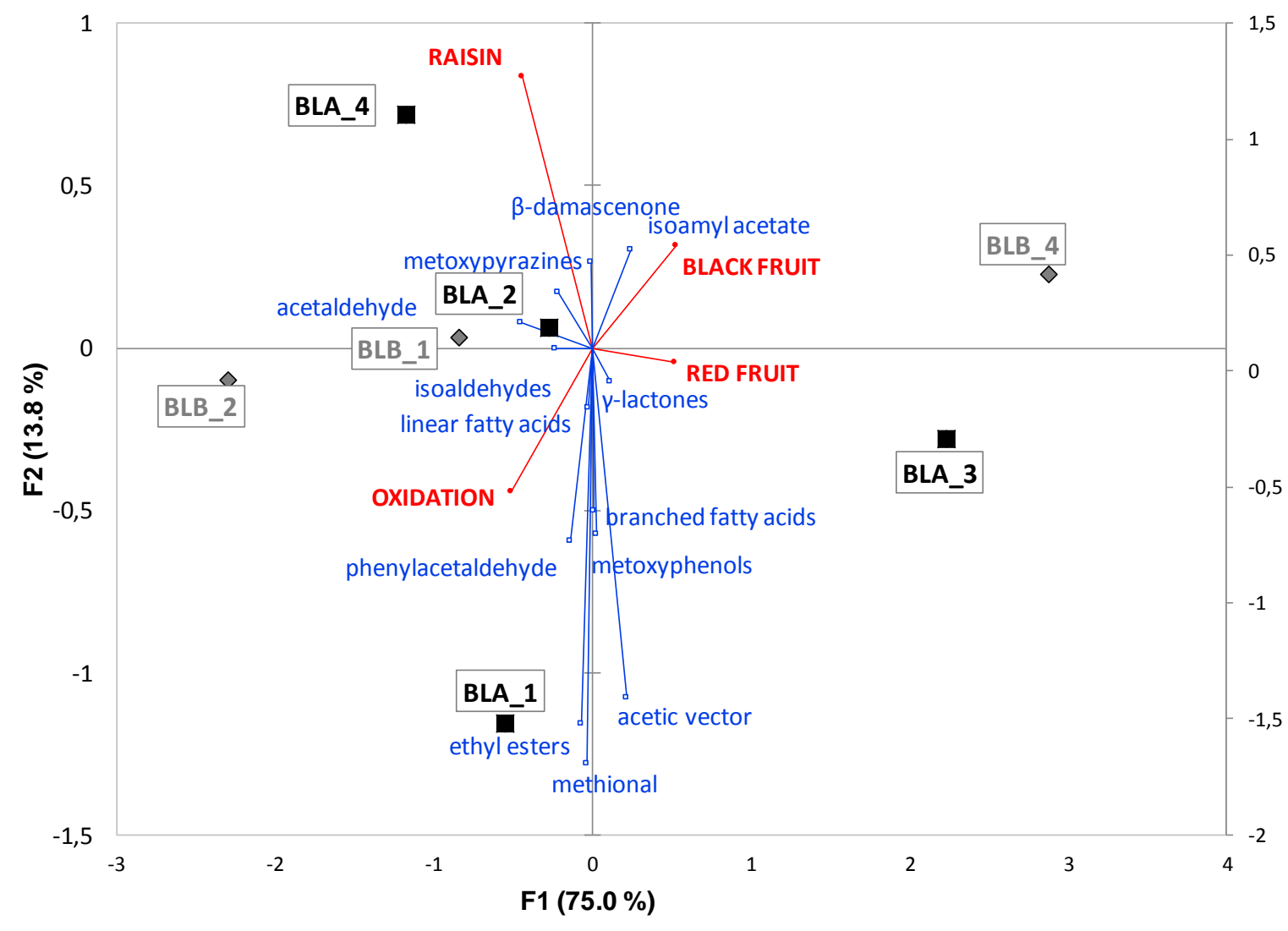

Figure 2 